\title{
On the properties of poly(isoprene-b-ferrocenylmethyl methacrylate) block copolymers
}

\author{
Chernyy, Sergey; Kirkensgaard, Jacob Judas Kain; Bakke, Anders; Mortensen, Kell; Almdal, Kristoffer
}

Published in:

Polymer

Link to article, DOI:

10.1016/j.polymer.2017.11.036

Publication date:

2017

Document Version

Peer reviewed version

Link back to DTU Orbit

Citation (APA):

Chernyy, S., Kirkensgaard, J. J. K., Bakke, A., Mortensen, K., \& Almdal, K. (2017). On the properties of poly(isoprene-b-ferrocenylmethyl methacrylate) block copolymers. Polymer, 133, 129-136.

https://doi.org/10.1016/j.polymer.2017.11.036

\section{General rights}

Copyright and moral rights for the publications made accessible in the public portal are retained by the authors and/or other copyright owners and it is a condition of accessing publications that users recognise and abide by the legal requirements associated with these rights.

- Users may download and print one copy of any publication from the public portal for the purpose of private study or research.

- You may not further distribute the material or use it for any profit-making activity or commercial gain

- You may freely distribute the URL identifying the publication in the public portal 


\section{Accepted Manuscript}

hit

\section{polymer}

On the properties of poly(isoprene-b-ferrocenylmethyl methacrylate) block copolymers

Sergey Chernyy, Jacob Judas Kain Kirkensgaard, Anders Bakke, Kell Mortensen, Kristoffer Almdal

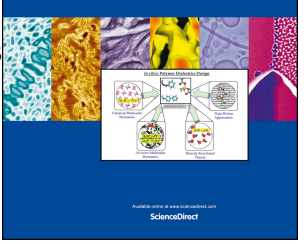

PII:

S0032-3861(17)31093-5

DOI:

10.1016/j.polymer.2017.11.036

Reference:

JPOL 20149

To appear in: Polymer

Received Date: 27 September 2017

Revised Date: 11 November 2017

Accepted Date: 15 November 2017

Please cite this article as: Chernyy S, Kirkensgaard JJK, Bakke A, Mortensen K, Almdal K, On the properties of poly(isoprene- $b$-ferrocenylmethyl methacrylate) block copolymers, Polymer (2017), doi: 10.1016/j.polymer.2017.11.036.

This is a PDF file of an unedited manuscript that has been accepted for publication. As a service to our customers we are providing this early version of the manuscript. The manuscript will undergo copyediting, typesetting, and review of the resulting proof before it is published in its final form. Please note that during the production process errors may be discovered which could affect the content, and all legal disclaimers that apply to the journal pertain. 


$$
\chi=0.12+0.19 / T
$$

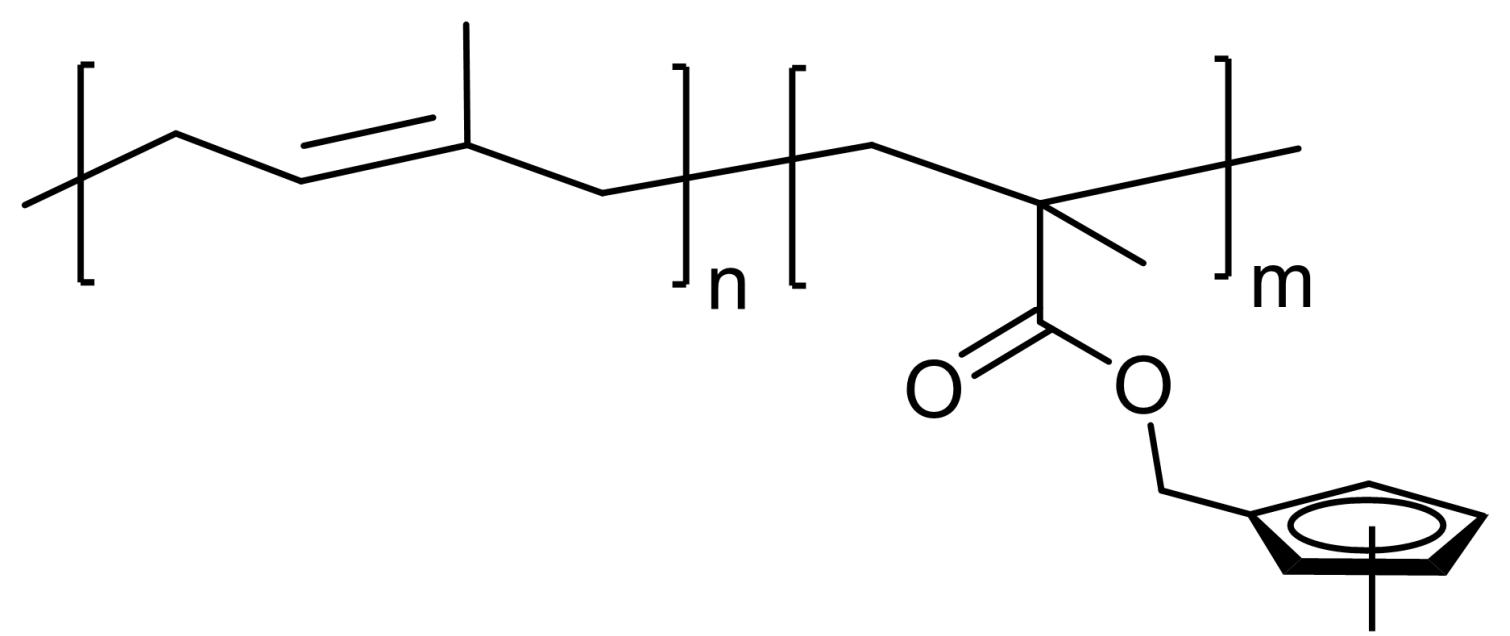

$\mathrm{Fe}$

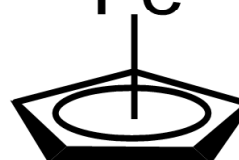


On the properties of poly(isoprene- $b$-ferrocenylmethyl methacrylate) block

copolymers

4 Sergey Chernyy, ${ }^{1}$ Jacob Judas Kain Kirkensgaard, ${ }^{2}$ Anders Bakke, ${ }^{2}$ Kell Mortensen, ${ }^{2}$ Kristoffer

Almdal $^{1}$

6

${ }^{1}$ Technical University of Denmark, DTU Nanotech - Department of Micro- and

Nanotechnology, Produktionstorvet, 2800 Kgs. Lyngby, Denmark

${ }^{2}$ Niels Bohr Institute, University of Copenhagen, 2100 Copenhagen, Denmark

$11 *$ Corresponding author

12 Sergey Chernyy

13 Email: sergeychernyy@gmail.com

14

15 Keywords

16 Ferrocenylmethyl methacrylate (FMMA), poly(1,4-isoprene), anionic polymerization, diblock

17 copolymers, Flory-Huggins interaction parameter, rheology, order-disorder transition. 
By combining poly(1,4-isoprene) (PI) with poly(ferrocenylmethyl methacrylate) (PFMMA) in a diblock copolymer structure by means of anionic polymerization we obtained narrowly dispersed PI- $b$-PFMMA copolymers with molecular weight ranging from 13000 to $62000 \mathrm{~g} / \mathrm{mol}$. The products were stable up to $228{ }^{\circ} \mathrm{C}$, according to thermal gravimetry, which allowed us to further investigate their viscoelastic and X-ray scattering properties at elevated temperature by rheology and SAXS, respectively. For PI-b-PFMMA with total molecular weight $13400 \mathrm{~g} / \mathrm{mol}$ a phase transition at $105^{\circ} \mathrm{C}$ was identified leading to the segmental mixing at $\mathrm{T}>105^{\circ} \mathrm{C}$ and microphase separation at $\mathrm{T}<105{ }^{\circ} \mathrm{C}$. The microphase separated morphology acquired hexahonally packed cylinder (HEX) microstructure in bulk. The explanation of the ordered HEX morphology was derived from a quantification of the thermodynamic immiscibility between PI and PFMMA segments via random phase approximation theory yielding generally accepted dependency of the Flory-Huggins interaction parameter $(\chi)$ on temperature.

\section{Introduction}

Methacrylate derivatives of ferrocene have attracted scientific interest since 1970 due to their ability to undergo rapid free radical polymerization and their numerous technologically important properties which originate from the organometallic group [1-3]. Polymers bearing ferrocenyl groups are redox-active and therefore widely applied in the areas of electrochemical sensing, molecular recognition and energy storage [4-6]. Linear and nonlinear optical properties could be modulated by linking ferrocene donors with acceptors [7]. Pyrolysis of the ferrocene-based polymers affords ceramics which are magnetically susceptible while oxygen plasma oxidation of thin films allows a direct access to nanostructured substrates [8-10].

The most typical example of methacrylate derivatives of ferrocene is poly(ferrocenylmethyl methacrylate) [PFMMA] which has been homopolymerized and copolymerized with a range of standard monomers [11]. Soon thereafter (1977) anionic homopolymerization of FMMA was reported by Pittman and Hirao affording lower polydispersity (PDI) compared to free-radically 
produced samples [12]. Surprisingly, no reports on successful anionic block copolymerization of FMMA were published until recently probably due to the challenging monomer purification step involved. In 2009 Gallei et al. studied PS- $b$-FMMA [poly(styrene)] and found that due to rather weak intersegment interactions the morphology of the produced diblock copolymers remained largely disordered in the bulk state [13]. It is worth mentioning in this context that the measure of segment-segment interaction energy is best described by the Flory-Huggins interaction parameter $(\chi)$. When $\chi$ is positive for a given diblock copolymer heterocontacts between segments are energetically unfavorable and demixing occurs. The demixing at a segmental level leads to microphase separation at the nanoscale, the extent of which depends on the product of $\chi$ and the total number of segments in a diblock copolymer $(\chi N)$. When $\chi N \gg 10.5$ strong segregation takes place and equilibrium morphologies have sharp boundaries between nanodomains while for $\chi N$ close to but larger than 10.5 partial segmental mixing at the interfaces leads to more diffuse boundaries [14-16]. We have shown in our previous report ${ }^{2}$ that combining in a diblock copolymer structure a perfluorinated methacrylate as a first block and PFMMA as a second block infers wellordered bulk and surface morphologies, even for low molecular weight, which indicates strong segregation/incompatibility between the two blocks.

The aim of these studies is to assess in a quantitative manner the intersegment incompatibility of PI- $b$-PFMMA [poly(1,4-isoprene)] diblock copolymers. For this purpose a series of PI- $b$-PFMMA diblock copolymers were synthesized and PI-PFMMA interactions ( $\left.\chi_{\text {PI-PFMMA }}\right)$ were ascertained using random phase approximation (RPA) theory. The choice of PI as a first block was not accidental. We [2] and others [13] have shown that no well-ordered morphologies are attainable when using classical styrene and methyl methacrylate (MMA) monomers to produce PMMA- $b$ PFMMA and PS- $b$-PFMMA copolymers. The third classical monomer is isoprene which is inexpensive and its polymerization kinetics is well established. Exploiting this advantage along with the fact that PI- $b$-PFMMA could undergo microphase separation affording long range order in bulk nanostructures we are convinced that PI- $b$-PFMMA copolymers developed herein are the first 
ACCEPTED MANUSCRIP'T

examples of functional diblock copolymer consisting of commercially available first block which makes it readily accessible for scaling up and further investigation.

\section{Materials and methods}

All chemicals were purchased from Sigma-Aldrich unless otherwise stated. Tetrahydrofuran (THF) was distilled from ketyl radical of benzophenone under argon. Cyclohexane was distilled from living poly(styryl)lithium under argon. Isoprene was consecutively distilled from calcium hydride $\left(\mathrm{CaH}_{2}\right)$ and di- $n$-butylmagnesium. FMMA was sublimed 7-10 times using cold finger in the dark at 0.001 mbar.

The PDI was determined by gel permeation chromatography (GPC) using THF with $1 \%$ triethylamine as an eluent at $0.5 \mathrm{ml} / \mathrm{min}$ flow rate with a column set consisting of a precolumn and two 300 × $8 \mathrm{~mm}$ main columns (PLgel Mixed C and Mixed D). Rheological characterization was realized on a Rheometrics solids analyzer (RSA II) operated with a $0.3 \mathrm{~mm}$ gap shear sandwich configuration at $1 \%$ shear strain $(\gamma)$ amplitude and $1 \mathrm{rad} / \mathrm{s}$ frequency $(\omega)$. Small-angle X-ray scattering (SAXS) profiles were measured using the SAXSLab instrument at the Niels Bohr Institute (NBI). After synthesis the samples were isolated by precipitation from a good solvent to a nonsolvent. Such procedure is equivalent to a quenching at infinitely high temperature and results in disordered bulk morphology. As prepared samples were further used for the SAXS measurements without additional treatment. The SAXSLab instrument uses a Rigaku 40W microfocused $\mathrm{Cu}$-source producing X-rays with a wavelength of $1.54 \AA$ which is detected by a moveable Pilatus 300k pixel-detector. A sample was mounted in small $\mathrm{Cu}$-discs between two 5-7 $\mu \mathrm{m}$ mica windows. The sample holder discs were connected to a Linkam HFS91 stage connected to a LNP95 temperature controller enabling temperature scans. Each temperature had a total measurement time of 15 minutes. The $q$ calibration of the instrument was done by using silver behenate as a reference. Two consecutive sets of SAXS measurements were performed on each sample, starting with 
measurements versus increasing temperatures, followed by a decreasing temperature scan. The

second set of SAXS measurements was performed to check reproducibility of phases from the first set. At each temperature, a total exposure time of 15 minutes was performed in three separate scans of 5 minutes.

Anionic polymerization. The experiments were realized using the anionic polymerization setup described elsewhere [17]. In our abbreviation of the block copolymer systems, we will index PI with the molar mass of the total diblock copolymer and the PFMMA will be indexed with the volume fraction of PFMMA. For the synthesis of PI- $b$-PFMMA diblock copolymer with a total molecular weight of $13 \mathrm{kDa}$, having a volume fraction of PFMMA block of 47\%, abbreviated as $\mathrm{PI}_{13 \mathrm{k}} \mathrm{F}_{47}$, the following procedure was adopted. A solution of isoprene $(1.2 \mathrm{~g})$ in cyclohexane $(0.17$ $\mathrm{g} / \mathrm{ml})$ was added to the mixture of $\mathrm{sec}$-butyllithium initiator $(0.24 \mathrm{mmol}, 1 \mathrm{x})$ and $100 \mathrm{ml}$ of cyclohexane in $1 \mathrm{~L}$ reactor and stirred for $10 \mathrm{~h}$ at $40{ }^{\circ} \mathrm{C}$ (overpressure!). A solution of produced living poly(isoprenyl)-Li was transferred to the second reactor containing $0.17 \mathrm{~g}(0.97,4 \mathrm{x})$ 1,1diphenyl ethylene (DPE), $0.051 \mathrm{~g}(1.21 \mathrm{mmol}, 5 \mathrm{x}) \mathrm{LiCl}$ and $200 \mathrm{ml}$ dry THF. After $1 \mathrm{~h}$ at $-15{ }^{\circ} \mathrm{C}$ reaction mixture was cooled down to $-78{ }^{\circ} \mathrm{C}$ and $1.7 \mathrm{~g}(6.0 \mathrm{mmol})$ of FMMA was added as a solution in THF $(0.07 \mathrm{~g} / \mathrm{ml})$. Polymerization of the second monomer was conducted for $1 \mathrm{~h}$ at -78 ${ }^{\circ} \mathrm{C}$, then $2 \mathrm{ml}$ of methanol was added and the diblock copolymer was precipitated to $800 \mathrm{ml}$ isopropanol. The precipitant was filtered and dried under vacuum in the dark at $50{ }^{\circ} \mathrm{C}$ for $16 \mathrm{~h}$ at 0.001 mbar. Yellowish semisolid product was thereby obtained in a quantitative yield.
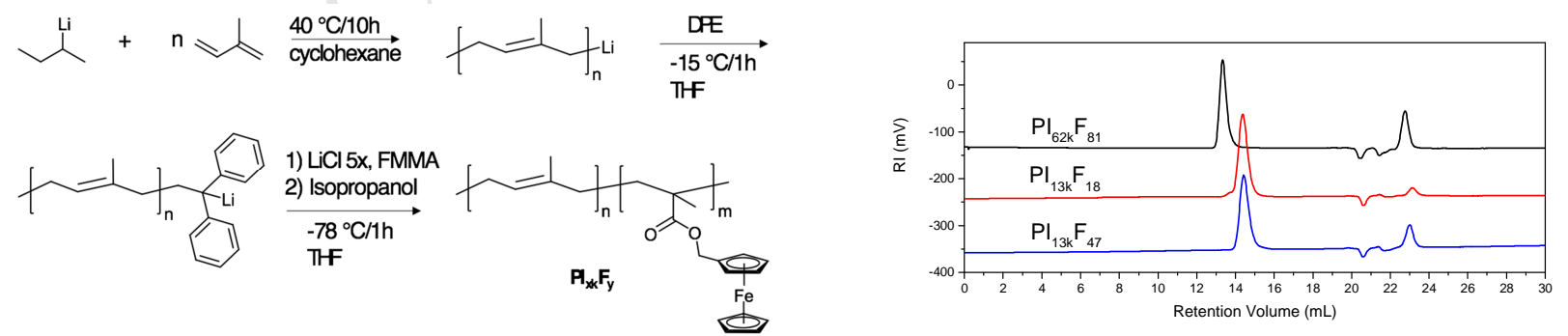

Scheme 1. Synthesis of PI- $b$-PFMMA ( $\mathrm{PI}_{\mathrm{xk}} \mathrm{F}_{\mathrm{y}}$ ) diblock copolymers (left) and the GPC curves (right) corresponding to the obtained polymers. In the name of the sample the first subscript denotes total molecular weight of the diblock copolymer while the second subscript signifies the average (from NMR and TGA) volume fraction (in \%) of the PFMMA block. 
Synthesis. The synthesis via anionic polymerization of the methacrylate containing monomers require intermediate capping of the poly(isoprenyl)lithium with 1,1-diphenyl ethylene to reduce the nucleophilicity of the growing centers which would otherwise be active enough towards carbonyl groups of the monomer/polymer. Molar excess $(5 \mathrm{x})$ of the $\mathrm{LiCl}$ compared to initiator was also used for the same purpose. In addition, an exhaustive monomer purification was performed either by distillation (isoprene) or repetitive sublimation (PFMMA) of the monomers to minimize termination of the growing chains with protic impurities. As a consequence, well-defined diblock copolymers could be obtained with polydispersities ranging from 1.04 to 1.07 (Table 1).

Table 1. Characteristics of the synthesized PFMMA homopolymer and diblock copolymers.

\begin{tabular}{lllllllll}
\hline Name $^{\mathrm{a}}$ & $\begin{array}{l}\mathrm{MW}, \\
\mathrm{kDa} \\
(\mathrm{NMR})\end{array}$ & $\begin{array}{l}\text { MW } \\
\mathrm{PFMMA}\end{array}$ & $\begin{array}{l}\text { PDI } \\
(\mathrm{GPC})\end{array}$ & $\begin{array}{l}\text { Residue at } \\
900^{\circ} \mathrm{C} \\
(\mathrm{TGA}), \%\end{array}$ & $\begin{array}{l}f_{\text {PFMMA }} \\
(\mathrm{NMR})\end{array}$ & $\begin{array}{l}f_{\text {PFMMA }} \\
(\mathrm{TGA})\end{array}$ & $\begin{array}{l}f_{\text {PFMMA }} \\
\text { average }\end{array}$ & $\begin{array}{l}\mathrm{Unm}^{\mathrm{b}} \\
\mathrm{nm}^{\mathrm{b}} \text { cell size, }\end{array}$ \\
\hline PFMMA & 45.8 & 45.8 & 1.15 & 25.2 & 1.00 & 1.00 & 1.00 & $\mathrm{n} / \mathrm{a}$ \\
$\mathrm{PI}_{62 \mathrm{k}} \mathrm{F}_{81}$ & 61.5 & 54.4 & 1.04 & 23.6 & 0.84 & 0.78 & 0.81 & 24.3 \\
$\mathrm{PI}_{13 \mathrm{k}} \mathrm{F}_{18}$ & 13.4 & 3.7 & 1.06 & 6.04 & 0.20 & 0.15 & 0.18 & 16.6 \\
$\mathrm{PI}_{13 \mathrm{k}} \mathrm{F}_{47}$ & 12.9 & 8.4 & 1.07 & 13.9 & 0.55 & 0.39 & 0.47 & 15.9 \\
\hline
\end{tabular}

${ }^{a}$ In the name of the sample the first subscript denotes total molecular weight of the diblock copolymer while the second subscript signifies the average (from NMR and TGA) volume fraction (in \%) of the PFMMA block estimated using the density of PFMMA and poly(1,4-isoprene) equal to $1.37 \mathrm{~g} / \mathrm{ml}$ and $0.91 \mathrm{~g} / \mathrm{ml}$ respectively.

${ }^{\mathrm{b}}$ Unit cell parameter calculated from SAXS as $d=2 \pi / q^{*}$ for lamellar (LAM) and $a=2 d / \sqrt{3}$ for hexagonally packed cylinders (HEX) morphologies where $q^{*}$ is the first order reflection. lower compared to PFMMA homopolymer which is attributed to the presence of poly(isoprene) in 139 the block copolymer structure. The temperature corresponding to the maximum rate of 140 decomposition $\left(T_{\max }\right)$ is equal to $454{ }^{\circ} \mathrm{C}$ for PFMMA while for the diblock copolymers it is within 141 the range $390-440{ }^{\circ} \mathrm{C}$ (Figure 1). Since upon decomposition PFMMA containing polymers in air 142 will form pure $\mathrm{Fe}_{2} \mathrm{O}_{3}$ as a residue [2], we could estimate the volume fractions $\left(f_{\text {PFMMA }}\right)$ of PFMMA 143 block from TGA data (see Table 1). The values obtained in such manner were averaged with NMR 


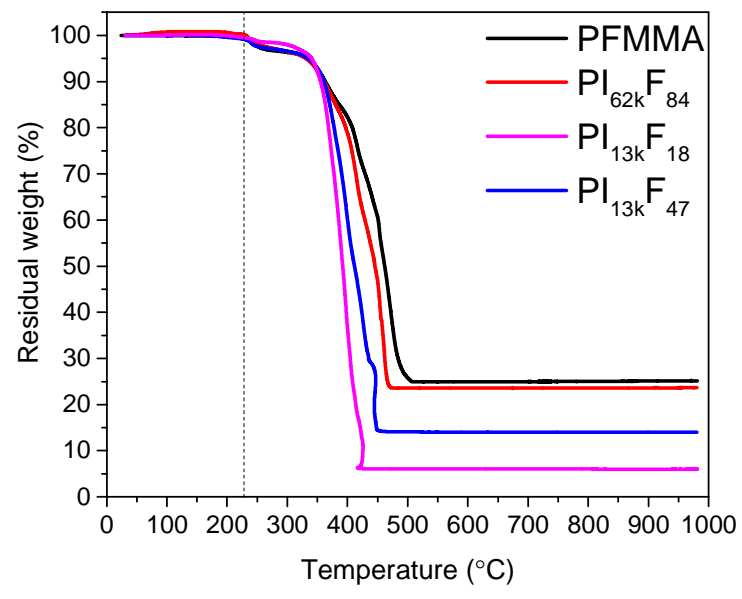

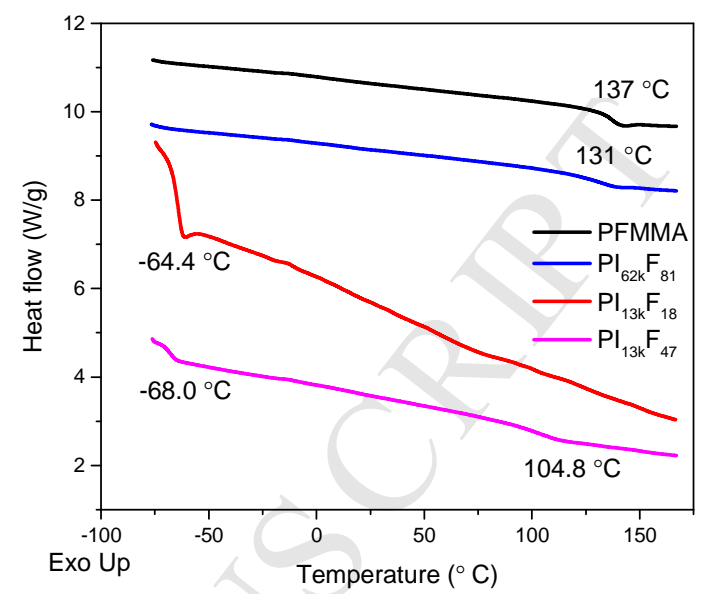

Figure 1. TGA (left, in air) and DSC (right, in $\mathrm{N}_{2}$ ) curves of the synthesized block copolymers recorded at $10^{\circ} \mathrm{C} / \mathrm{min}$ demonstrating (TGA) plateau after $\sim 500{ }^{\circ} \mathrm{C}$ due to $\mathrm{Fe}_{2} \mathrm{O}_{3}$ residue and (DSC) glass transition dependence of the diblock copolymer on the composition. Only the second DSC scan is shown for every sample. Glass transition temperatures are estimated by curve differentiation method.

DSC data reveal the presence of poly(isoprene) characterized by a low glass transition temperature $\left(T_{\mathrm{g}}\right)$ equal to $-64.4{ }^{\circ} \mathrm{C}$ and $-68.0{ }^{\circ} \mathrm{C}$ for the case of $\mathrm{PI}_{13 \mathrm{k}} \mathrm{F}_{18}$ and $\mathrm{PI}_{13 \mathrm{k}} \mathrm{F}_{47}$ respectively. Subtle $T_{\mathrm{g}}$ variations for PI block reflect the influence of the second PFMMA block on the glass transition of the first block. Similar phenomena is observed at the high temperature end. Pure PFMMA glass transition occurs at $137{ }^{\circ} \mathrm{C}$ while the presence of PI reduces $T_{\mathrm{g}}$ to $131{ }^{\circ} \mathrm{C}$ for $\mathrm{PI}_{62 \mathrm{k}} \mathrm{F}_{81}$. Even lower $T_{\mathrm{g}}\left(104.8^{\circ} \mathrm{C}\right)$ was found for $\mathrm{PI}_{13 \mathrm{k}} \mathrm{F}_{47}$ which is thought to be caused by low molecular weight of the PFMMA block $(8.4 \mathrm{kDa})$. Such phenomena is well-documented for, e.g., poly(styrene) that exhibits $T_{\mathrm{g}}$ reduction as a function of finitely low chain length [18].

Rheology. Isochronal temperature scans [19-21] for diblock copolymers are presented in Figure 2. When the temperature is below $\sim 140{ }^{\circ} \mathrm{C}$ the polymer chains are in a glassy state which is characterized by high storage modulus values $\left(10^{6} \mathrm{~Pa}\right)$ and domination of the elastic over viscous behavior $\left(G^{\prime}>G^{\prime \prime}\right)$. After the glass transition the chains acquire sufficient mobility and microphase separation becomes feasible via diffusion of the PI and PFMMA blocks in the molten state. In the 
166 softening of the polymers occurs until almost liquid-like state is reached at ca. $200{ }^{\circ} \mathrm{C}$ followed by a crosslinking at higher temperatures. On the other hand, for $\mathrm{PI}_{13 \mathrm{k}} \mathrm{F}_{18}$ sample an interesting accompanied by a sharp decrease of both $G^{\prime}$ and $G^{\prime \prime}$ to negligibly low values which are beyond the segments are overcome by an excess of heat supplied to the system at elevated temperature.

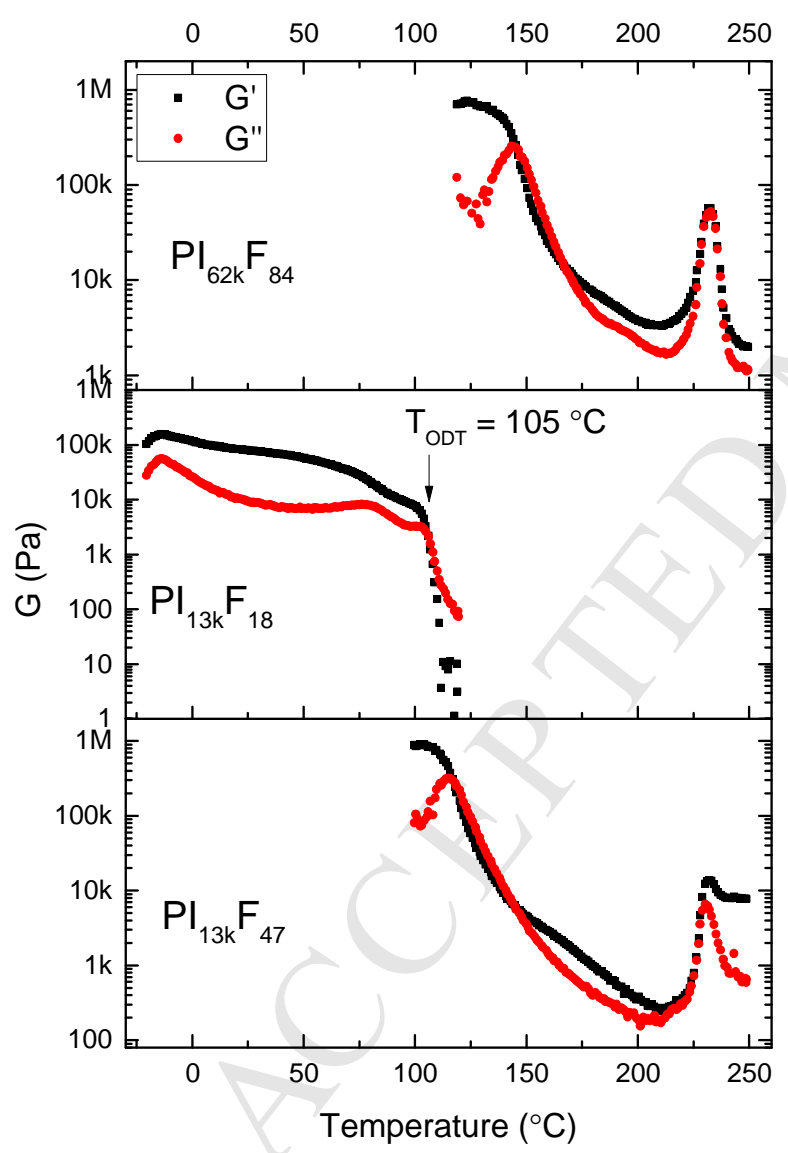

Figure 2. Isochronal $(\omega=1 \mathrm{rad} / \mathrm{s})$ dynamic storage $\left(G^{\prime}\right)$ and loss $\left(G^{\prime \prime}\right)$ moduli measured at $2{ }^{\circ} \mathrm{C} / \mathrm{min}$ heating rate and constant shear strain $\left(\gamma=1 \%\right.$ ) showing the glass transition (decrease in $\left.G^{\prime}, G^{\prime \prime}\right)$, the order-to-disorder transition (sharp drop in $G^{\prime}, G^{\prime \prime}$ at $105^{\circ} \mathrm{C}$ ) as well as crosslinking phenomena (increase in $\left.G^{\prime}, G^{\prime \prime}\right)$.

177 SAXS. The scattering profiles at varied temperature for the sample $\mathrm{PI}_{62 \mathrm{k}} \mathrm{F}_{81}$, are shown on Figure

178 3. The data clearly demonstrate the transition from powder scattering below $\mathrm{T}=155^{\circ} \mathrm{C}$ to scattering 
$q^{-3.9}$ power law, which is in a good agreement with the $q^{-4}$ slope for powdery samples dominated by

181 surface scattering. The statistical error-bars on the slope is rather small, below \pm 0.002 , however with the relative small $q$-range where the Porod-scattering is dominant, the fit result is rather dependent on the exact range that is fitted. Including such systematic errors, we estimate the error bar to be 0.2 . Further increase in the temperature leads to enhanced chain mobility and bulk structuring of the sample as exemplified by appearance of higher order reflections. The positions of the second and third peaks coincide with hexagonally packed cylinder (HEX) morphology which is in agreement with the volume fraction of the PFMMA component (81\%) in the diblock copolymer. a $24 \mathrm{~nm}$ unit cell where the cylinder volume is ca. $20 \%$ as here (minimum around $0.06-0.07 \AA^{-1}$ ).

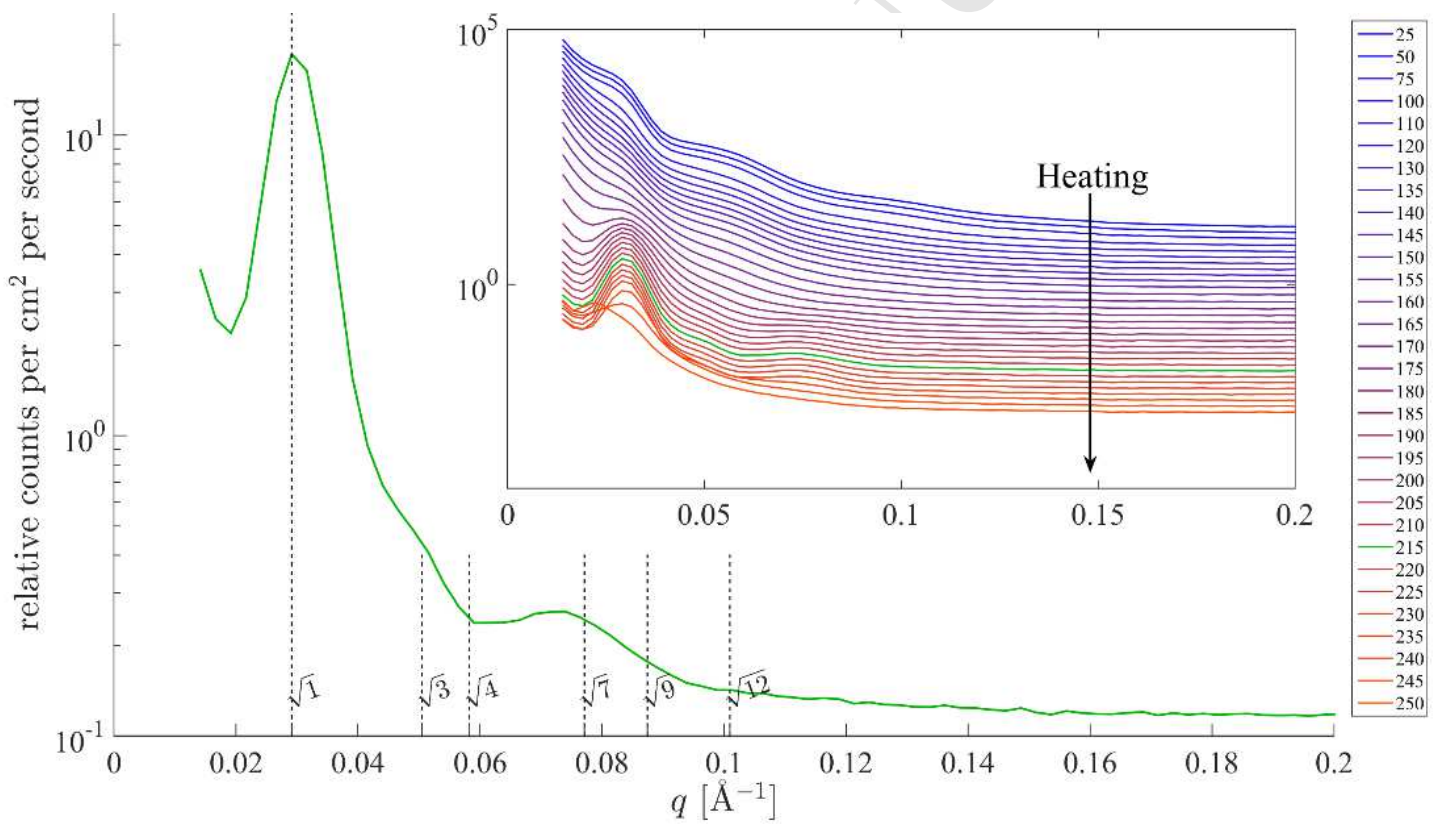

Figure 3: SAXS data for the sample $\mathrm{PI}_{62 \mathrm{k}} \mathrm{F}_{81}$ acquired at $215{ }^{\circ} \mathrm{C}$ with the dashed lines marking relative peak distances for a $\mathrm{HEX}$ morphology. The inset shows SAXS profiles measured during in-situ temperature scans from 25 to $250{ }^{\circ} \mathrm{C}$.

SAXS measurements performed at varied temperature for the sample $\mathrm{PI}_{13 \mathrm{k}} \mathrm{F}_{18}$ confirm the location of $T_{\mathrm{ODT}}$ between 105 and $110{ }^{\circ} \mathrm{C}$ which is in excellent agreement with the rheology data (Figure 4). At the proximity to ODT second and third order reflection peaks appear indicating the formation of the well-ordered morphology. The relative peak positions $\left(q / q^{*}=1: \sqrt{3}: \sqrt{4}\right)$ correspond to the HEX, where PFMMA being the minority domains forms cylinders and majority 
of PI forms the surrounding matrix. In this case the form factor minimum is shifted out to ca. $0.1 \AA^{-}$

$200{ }^{1}$ so the $\sqrt{4}$ peak is now visible. The first heating cycle (Figure $4 \mathrm{~A}$ ) was terminated at $120{ }^{\circ} \mathrm{C}$ by 201 cooling the sample to room temperature to avoid excessive polymer degradation. While cooling, 202 disordered, segmentally mixed $\mathrm{PI}_{13 \mathrm{k}} \mathrm{F}_{18}$ sample undergoes microphase separation leading to the 203 same HEX morphology which becomes permanently fixed after crossing $T_{\mathrm{g}}$ of the PFMMA block.
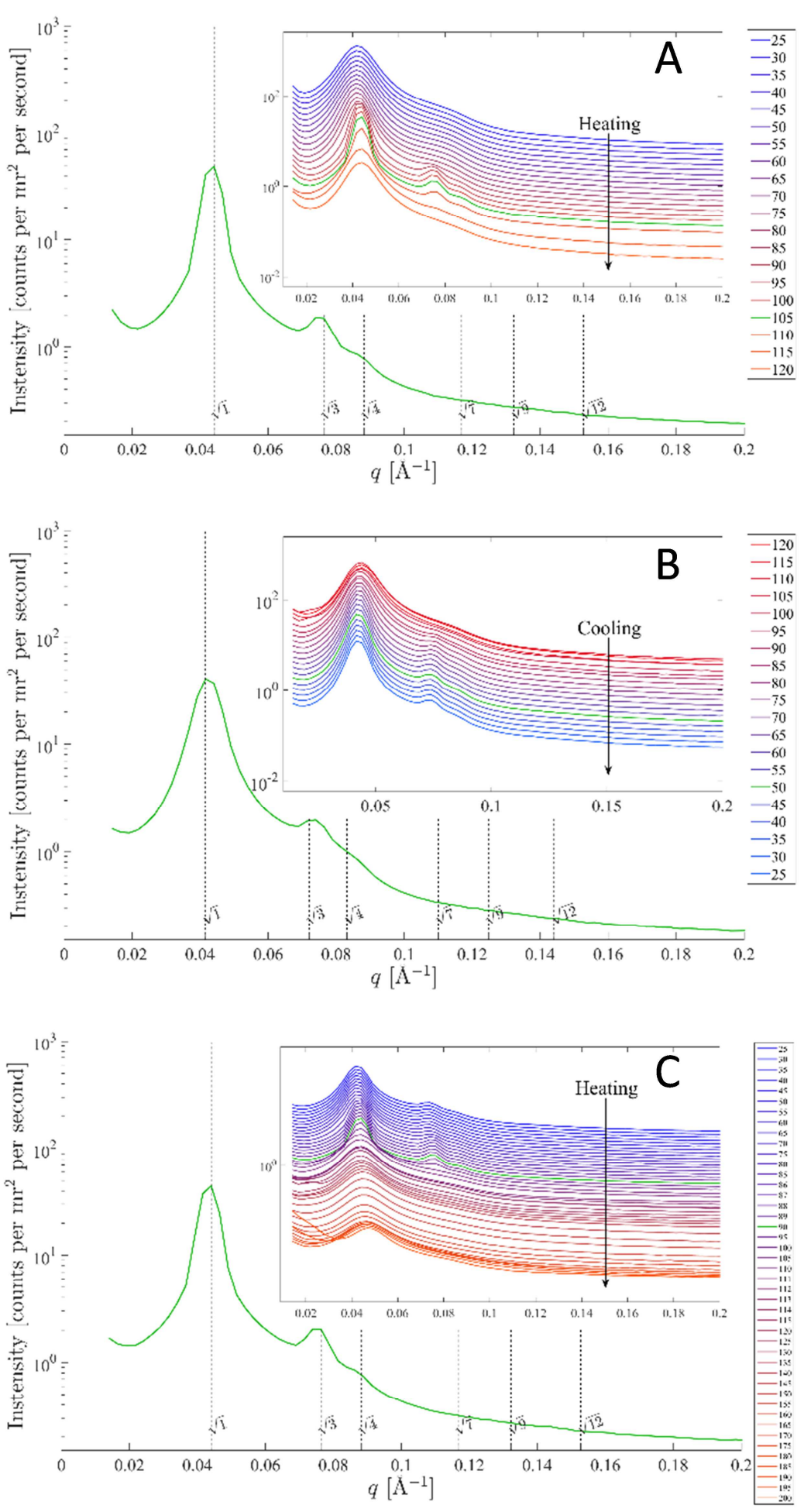
CCEPTED IVIANUSCRIPT

Figure 4. SAXS temperature scans of the $\mathrm{PI}_{13 \mathrm{k}} \mathrm{F}_{18}$ sample acquired at (A) $105{ }^{\circ} \mathrm{C}$, (B) $50{ }^{\circ} \mathrm{C}$ and (C) $90{ }^{\circ} \mathrm{C}$. (A) Data from first heating cycle showing the transition from disordered to ordered and back to disordered state and (B) first cooling cycle where after disorder-to-order transition the microphase separated structure is fixed in a glassy state. Blue lines indicate colder while red indicates warmer temperatures. (C) Heating to higher temperature $\left(200^{\circ} \mathrm{C}\right)$ in the second heating cycle to collect more data in the disordered state for RPA fitting.

The second heating cycle (Figure 4C) was terminated at $200{ }^{\circ} \mathrm{C}$ and a wide range of data in the

disordered state above the ODT was acquired. This allowed us to fit the experimental scattering data with random phase approximation theory (RPA) and thereby estimate the Flory-Huggins interaction parameter, $\chi[22,23]$. The RPA prediction for the scattering intensity of a disordered diblock copolymer melt is

$$
I(q)=\left(\frac{b_{1}}{v_{1}}-\frac{b_{2}}{v_{2}}\right)^{2}\left[\frac{S_{11}^{0}+S_{22}^{0}+2 S_{12}^{0}}{S_{11}^{0} S_{22}^{0}-\left(S_{12}^{0}\right)^{2}}-\frac{2 \chi}{v_{R}}\right]^{-1}
$$

217 here set to $v_{R}=118 \AA^{3}$ and $b_{i}$ and $v_{i}$ are the scattering lengths and molecular volumes of the polymers calculated as follows:

$$
\begin{aligned}
& b_{i}=Z_{i} r_{e} \\
& v_{i}=\frac{M_{w, i}}{d N_{a}}
\end{aligned}
$$

where $Z$ is the number of electrons in the monomer $i, r_{e}$ is the classical Thomson scattering length $221\left(2.82 \times 10^{-13} \mathrm{~cm}\right), M_{w}$ is the molecular weight of the monomer $i, d$ is the polymer density and $N_{a}$ is the Avogadro number.

223 Finally, $S_{i i}^{0}$ are the correlation functions between the blocks given by

$$
S_{i i}^{0}=\phi_{i} N_{i} v_{i} P_{i}(q)
$$

224 and

$$
S_{12}^{0}=\left(\phi_{1} N_{1} v_{1} \phi_{2} N_{2} v_{2}\right)^{1 / 2} F_{1}(q) F_{2}(q)
$$


Here $\phi_{i}$ and $N_{i}$ are the volume fractions and number of monomers of the blocks and $P_{i}(q)$ and $F_{i}(q)$ are the intrablock and interblock correlations respectively given by

$$
\begin{gathered}
P_{i}(q)=2 \frac{\exp \left(-u_{i}\right)-1+u_{i}}{u_{i}^{2}} \\
F_{i}(q)=\frac{1-\exp \left(-u_{i}\right)}{u_{i}} \\
u_{i}=\frac{q^{2} N_{i} l_{i}^{2}}{6}
\end{gathered}
$$

where $l_{i}$ is the statistical segment length of block $i$. All parameters are known (Table 2) except the statistical segment length and the $\chi$-parameter, thus, these are the parameters to be determined by

229 fitting.

Table 2. Structural parameters for the $\mathrm{PI}_{13 \mathrm{k}} \mathrm{F}_{18}$ sample used for the $\chi$ parameter estimation.

\begin{tabular}{l|l} 
Parameter & Value \\
\hline$v_{R}$ & $118 \AA^{3}$ \\
$b_{1}$ & $1.07 \cdot 10^{-3} \AA$ \\
$b_{2}$ & $4.17 \cdot 10^{-3} \AA$ \\
$v_{1}$ & $124 \AA^{3}$ \\
$v_{2}{ }^{*}$ & $345 \AA^{3}$ \\
$\phi_{1}{ }^{*}$ & 0.8 \\
$\phi_{2} N_{1}$ & 0.2 \\
$N_{2}$ & 143 \\
\hline \multicolumn{2}{|c}{ *NMR based volume fractions were used. }
\end{tabular}

We fit the data to Equation 1 minimizing the square of the residuals using nonlinear minimization routines in Matlab. As Equation 1 only applies in the disordered state we only have a 234 suitable temperature range for the $\mathrm{PI}_{13 \mathrm{k}} \mathrm{F}_{18}$ sample, where $T>T_{\mathrm{ODT}}$. We found that the data range from $105{ }^{\circ} \mathrm{C}$ to $140{ }^{\circ} \mathrm{C}$ could be described by a linear fit. Figure $5 \mathrm{~A}$ shows an example of a fit of the first order peak at $130{ }^{\circ} \mathrm{C}$ and Figures $5 \mathrm{~B}, \mathrm{C}$ provide the linear inverse temperature dependence of the fitting parameters assuming that the statistical segment lengths of both arms are equal $\left(l_{1}=\right.$ $238 l_{2}=l$ ). This analysis gives dependency 9 where $T$ is in Kelvins:

$$
\chi=0.12+0.19 / T
$$



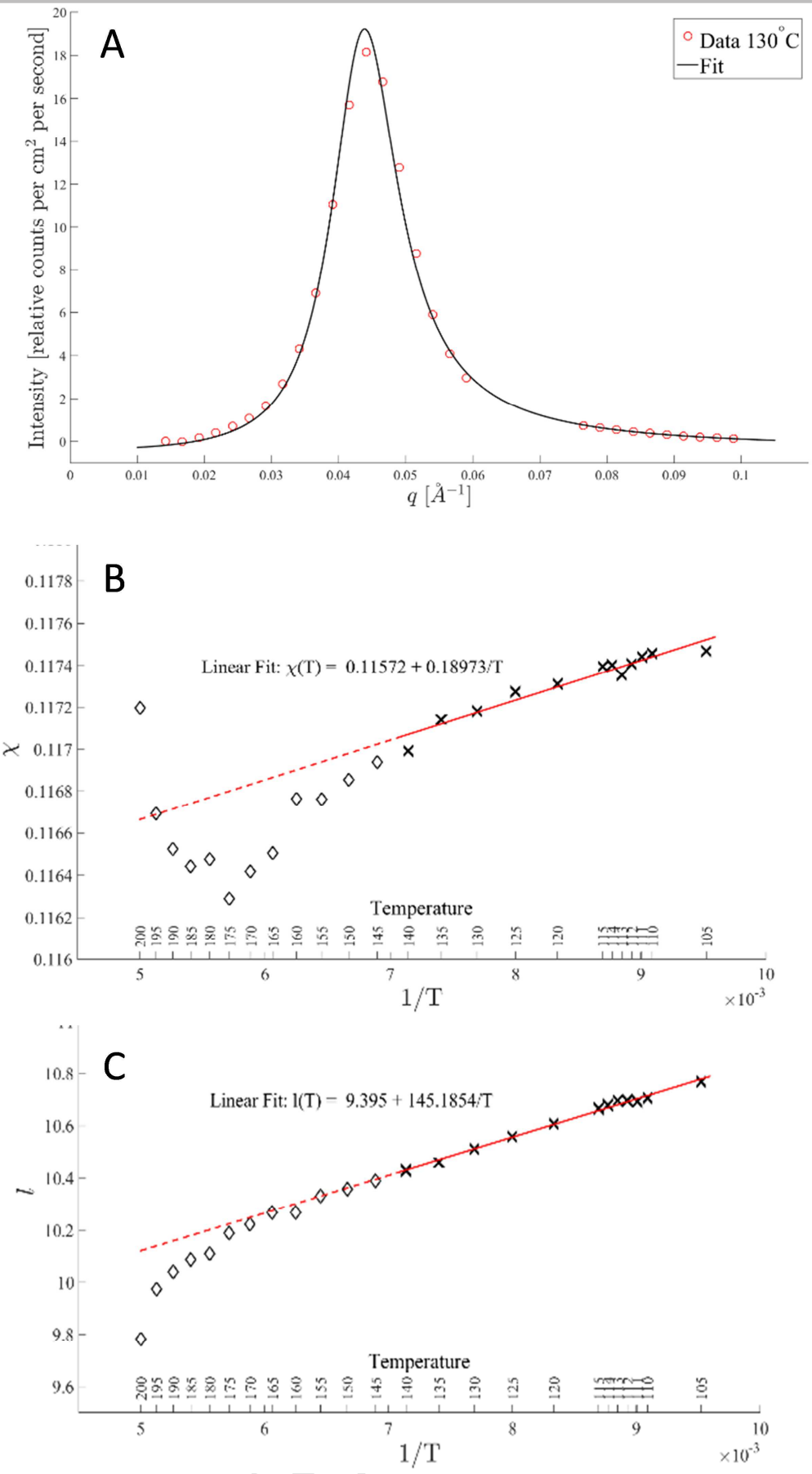

Figure 5. (A) RPA fit of the scattering data from the $\mathrm{PI}_{13 \mathrm{k}} \mathrm{F}_{18}$ sample at $130^{\circ} \mathrm{C}$. Temperature dependence of (B) $\chi$ and (C) $l$.

The resulting $\chi$ values and are affected by the background treatment in the SAXS profiles to a minor extent. We found that subtracting the background individually from each SAXS profile using a decaying exponential plus a polynomial of $n^{\text {th }}$ order plus a constant yielded the most reproducible results. We also found a shoulder on all our measurements at the right-hand side of the primary peak located at around 1.4 times $q^{*}$. Such a shoulder has been observed before [25] and was found on all data sampled in the disordered state with an amplitude inversely proportional to temperature. 
The origin of this shoulder is composition fluctuations near the ODT as discussed in detail by Bates et al. [25, 26]. These fluctuations are also shown in Ref. [26] to be persistent for a significant temperature interval above the order-disorder transition temperature which we confirm here. Such fluctuations are not accounted for in the mean-field based RPA which will thus not produce the observed shoulder. Furthermore, the effects from polydispersity in the sample and instrumental resolution on estimated $\chi$ values were assessed as described by Almdal et al. [26] and Pedersen et al. [27] respectively. Accounting for both PDI and instrumental resolution led to negligibly small variations in the resulting $\chi$-values which differed only in the $3^{\text {rd }}$ decimal.

Hence, from our measurements and analysis at the standard reporting temperature, $150{ }^{\circ} \mathrm{C}$, we estimate $\chi_{150^{\circ} \mathrm{C}}=0.12$ for the PI-PFMMA pair. Typically $150{ }^{\circ} \mathrm{C}$ is chosen as a standard temperature because it is above $T_{\mathrm{g}}$ but still below the degradation temperature of most of the known polymers [24]. The estimated $\chi$ value $\left(\chi_{150^{\circ} \mathrm{C}}=0.12\right)$ is identical to the PS-P2VP [17] interaction parameter $\left(\chi_{150^{\circ} \mathrm{C}}=0.12\right)$ but higher than that of PS-PI [28] $\left(\chi_{150^{\circ} \mathrm{C}}=0.08\right)$ and PS-PFS [23] $\left(\chi_{150^{\circ} \mathrm{C}}=0.03\right)$ pairs indicating significant incompatibility between PI and PFMMA segments.

Moreover, our analysis suggests that the average statistical segment length, $l$, is in the range 10.0

- $10.7 \AA$, which agrees well with the values previously reported by Eitouni et al. [23] who also investigated diblock copolymers of poly(styrene- $b$-ferroscenyldimethylsilane) from the organometallic group.

SAXS measurements performed at different temperatures for the sample $\mathrm{PI}_{13 \mathrm{k}} \mathrm{F}_{47}$ shows relative featureless scattering (Figure 6). Only in a narrow temperature range between $205{ }^{\circ} \mathrm{C}-210{ }^{\circ} \mathrm{C}$, some higher-order peaks are observed around $q=0.075$ and $0.13 \AA^{-1}$. The structure associated with these peaks suggests a lamellar morphology as would be expected for a diblock copolymer with symmetric composition. 


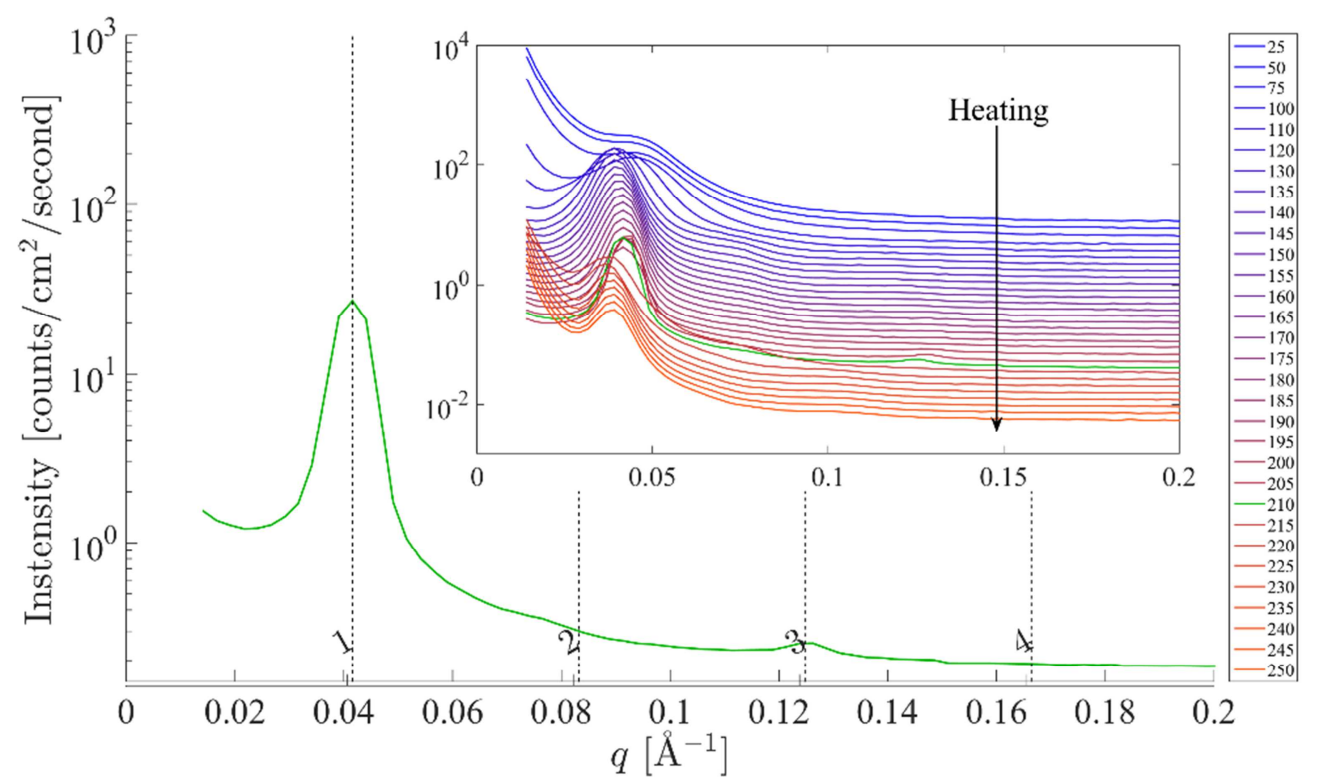

Figure 6: X-ray scattering profile acquired at $210{ }^{\circ} \mathrm{C}$ for the $\mathrm{PI}_{13 \mathrm{~K}} \mathrm{~F}_{47}$ sample demonstrating higher-order reflections at $q=0.075 \AA^{-1}$ and $q=0.13 \AA^{-1}$ which match the relative peak positions (represented by vertical dashed lines) of lamellae morphology. The inset shows SAXS profiles measured during in-situ temperature scans from 25 to $250{ }^{\circ} \mathrm{C}$.

\section{Conclusions}

Synthesized PI- $b$-PFMMA copolymers were subjected to temperature scans while monitoring equal to $3700 \mathrm{~g} / \mathrm{mol}$ exhibited the presence of an order-to-disorder transition at $105{ }^{\circ} \mathrm{C}$. This allowed us to derive a generally accepted dependency of the Flory-Huggins interaction parameter $(\chi)$ on temperature. Apart from fundamental interest about thermodynamic incompatibility between PI and PFMMA components, knowing absolute value of $\chi$ at a given temperature allows anyone to predict an equilibrium domain spacing, pitch size and minimum molecular weight which would be required to achieve microphase separation in bulk [24].

\section{Acknowledgements}

292 Authors are thankful to Villum Foundation for the financial support of the project. 


\section{References}

[1] C.U. Pittman, J.C. Lai, D.P. Vanderpool, Kinetics of Ferrocenylmethyl Acrylate and Ferrocenylmethyl Methacrylate Polymerization. Preparation of Polymeric Ferricinium Salts, Macromolecules 3(1) (1970) 105-107.

[2] S. Chernyy, Z. Wang, J.J.K. Kirkensgaard, A. Bakke, K. Mortensen, S. Ndoni, K. Almdal, Synthesis and Characterization of Ferrocene Containing Block Copolymers, J. Polym. Sci., Part A: Polym. Chem. In press (2016) DOI: 10.1002/pola.28435.

[3] R.L.N. Hailes, A.M. Oliver, J. Gwyther, G.R. Whittell, I. Manners, Polyferrocenylsilanes: synthesis, properties, and applications, Chem. Soc. Rev. 45(19) (2016) 5358-5407.

[4] R. Sun, L. Wang, H. Yu, Z.-u. Abdin, Y. Chen, J. Huang, R. Tong, Molecular Recognition and Sensing Based on Ferrocene Derivatives and Ferrocene-Based Polymers, Organometallics 33(18) (2014) 4560-4573.

[5] M. Saleem, H. Yu, L. Wang, A. Zain ul, H. Khalid, M. Akram, N.M. Abbasi, J. Huang, Review on synthesis of ferrocene-based redox polymers and derivatives and their application in glucose sensing, Anal. Chim. Acta 876(Supplement C) (2015) 9-25.

[6] E.S. Beh, D. De Porcellinis, R.L. Gracia, K.T. Xia, R.G. Gordon, M.J. Aziz, A Neutral pH Aqueous Organic-Organometallic Redox Flow Battery with Extremely High Capacity Retention, ACS Energy Letters 2(3) (2017) 639-644.

[7] S. Kaur, S. Dhoun, G. Depotter, P. Kaur, K. Clays, K. Singh, Synthesis, linear and nonlinear optical properties of thermally stable ferrocene-diketopyrrolopyrrole dyads, RSC Advances 5(103) (2015) 84643-84656.

[8] J. Shi, C.J.W. Jim, F. Mahtab, J. Liu, J.W.Y. Lam, H.H.Y. Sung, I.D. Williams, Y. Dong, B.Z. Tang, Ferrocene-Functionalized Hyperbranched Polyphenylenes: Synthesis, Redox Activity, Light Refraction, Transition-Metal Complexation, and Precursors to Magnetic Ceramics, Macromolecules 43(2) (2010) 680-690.

[9] M. Hmyene, A. Yassar, M. Escorne, A. Percheron-Guegan, F. Garnier, Magnetic properties of ferrocene-based conjugated polymers, Adv. Mater. 6(7-8) (1994) 564-568.

[10] R.G.H. Lammertink, M.A. Hempenius, V.Z.H. Chan, E.L. Thomas, G.J. Vancso, Poly(ferrocenyldimethylsilanes) for Reactive Ion Etch Barrier Applications, Chem. Mater. 13(2) (2001) 429-434.

[11] J.C. Lai, T.D. Rounsefell, C.U. Pittman, Copolymerization of Ferrocenylmethyl Acrylate and Ferrocenylmethyl Methacrylate with Organic Monomers, Macromolecules 4(2) (1971) 155-161.

[12] C.U. Pittman, A. Hirao, Anionic homopolymerization of ferrocenylmethyl methacrylate, J. Polym. Sci. A Polym. Chem. 15(7) (1977) 1677-1686.

[13] M. Gallei, B.V. Schmidt, R. Klein, M. Rehahn, Defined Poly[styrene-block-(ferrocenylmethyl methacrylate)] Diblock Copolymers via Living Anionic Polymerization, Macromol. Rapid Commun. 30(17) (2009) 1463-1469.

[14] C.M. Bates, M.J. Maher, D.W. Janes, C.J. Ellison, C.G. Willson, Block Copolymer Lithography, Macromolecules 47(1) (2014) 2-12.

[15] M.D. Rodwogin, C.S. Spanjers, C. Leighton, M.A. Hillmyer, Polylactide-Poly(dimethylsiloxane)-Polylactide Triblock Copolymers as Multifunctional Materials for Nanolithographic Applications, ACS Nano 4(2) (2010) 725-732.

[16] M.W. Matsen, F.S. Bates, Unifying Weak- and Strong-Segregation Block Copolymer Theories, Macromolecules 29(4) (1996) 1091-1098. 


\section{ACCEPTED MANUSCRIPT}

[17] M.F. Schulz, A.K. Khandpur, F.S. Bates, K. Almdal, K. Mortensen, D.A. Hajduk, S.M. Gruner, Phase Behavior of Polystyrene-Poly(2-vinylpyridine) Diblock Copolymers, 341 Macromolecules 29(8) (1996) 2857-2867.

[18] P. Claudy, J.M. Létoffé, Y. Camberlain, J.P. Pascault, Glass transition of polystyrene versus molecular weight, Polym. Bull. 9(4) (1983) 208-215.

[19] J. Zhao, B. Majumdar, M.F. Schulz, F.S. Bates, K. Almdal, K. Mortensen, D.A. Hajduk, S.M. Gruner, Phase Behavior of Pure Diblocks and Binary Diblock Blends of Poly(ethylene)-Poly(ethylethylene), Macromolecules 29(4) (1996) 1204-1215.

[20] S. Foerster, A.K. Khandpur, J. Zhao, F.S. Bates, I.W. Hamley, A.J. Ryan, W. Bras, Complex phase behavior of polyisoprene-polystyrene diblock copolymers near the order-disorder transition, Macromolecules 27(23) (1994) 6922-6935.

[21] J.L. Adams, W.W. Graessley, R.A. Register, Rheology and the microphase separation transition in styrene-isoprene block copolymers, Macromolecules 27(21) (1994) 6026-6032.

[22] C.C. Lin, S.V. Jonnalagadda, P.K. Kesani, H.J. Dai, N.P. Balsara, Effect of Molecular Structure on the Thermodynamics of Block Copolymer Melts, Macromolecules 27(26) (1994) 7769-7780.

[23] H.B. Eitouni, N.P. Balsara, H. Hahn, J.A. Pople, M.A. Hempenius, Thermodynamic Interactions in Organometallic Block Copolymers: Poly(styrene-block-ferrocenyldimethylsilane), Macromolecules 35(20) (2002) 7765-7772.

[24] C. Sinturel, F.S. Bates, M.A. Hillmyer, High $\chi$-Low N Block Polymers: How Far Can We Go?, ACS Macro Letters 4(9) (2015) 1044-1050.

[25] F.S. Bates, J.H. Rosedale, G.H. Fredrickson, Fluctuation effects in a symmetric diblock copolymer near the order-disorder transition, J. Chem. Phys. 92(10) (1990) 6255-6270.

[26] K. Almdal, F.S. Bates, K. Mortensen, Order, disorder, and fluctuation effects in an asymmetric poly (ethylene-propylene)-poly (ethylethylene) diblock copolymer, J. Chem. Phys. 96(12) (1992) 9122-9132.

[27] J.S. Pedersen, D. Posselt, K. Mortensen, Analytical treatment of the resolution function for small-angle scattering, J. Appl. Crystallogr. 23(4) (1990) 321-333.

[28] A.K. Khandpur, S. Foerster, F.S. Bates, I.W. Hamley, A.J. Ryan, W. Bras, K. Almdal, K. Mortensen, Polyisoprene-Polystyrene Diblock Copolymer Phase Diagram near the Order-Disorder Transition, Macromolecules 28(26) (1995) 8796-8806. 
- Poly(isoprene-b-ferrocenylmethyl methacrylate) diblock copolymers are investigated

- Order-to-disorder transition is detected for $13400 \mathrm{~g} / \mathrm{mol}$ sample at $105^{\circ} \mathrm{C}$

- Random phase approximation theory could therefore be applied

- Dependency of the Flory-Huggins interaction parameter on temperature is derived 